\section{Entre migraçóes, maternidades transnacionais e mídias}

Mirca MADIANOU \& Daniel MILLER. Migration and new media: transnational families and polymedia. Londres/Nova York, Routledge, 2012. 175 páginas.

\section{Bruna Louzada Bumachar}

Como pais e filhos cuidam uns dos outros quando separados por anos pela migração transnacional? Essa questão é o portão de embarque do leitor para Migration and new media: transnational families and polymedia, de Mirca Madianou e Daniel Miller. O livro é resultado de uma pesquisa multissituada e de longa duração (2007-2010) e trás uma etnografia substancial sobre as novas mídias e a natureza das relações sociais mediadas, sem que uma temática tenha prioridade sobre a outra. A partir da relação entre filipinas residentes na Inglaterra e seus filhos residentes nas Filipinas (left-behind children), os autores apresentam um novo tipo de "família transnacional conectada”, resultante da convergência de dois fenômenos: a migração transnacional e a explosão das oportunidades comunicativas proporcionadas pelas novas mídias.

O fenômeno das migrações transnacionais nas Filipinas não é novo, nem a decorrente constituição de famílias neste contexto. Contudo, a ideia de que vivemos um momento de multiplicação dessa experiência se faz presente logo no início da leitura. De acordo com dados oficiais apresentados no capítulo 2, "The Philippines and globalisation: migration, mothering and communication", cerca de $10 \%$ a $15 \%$ dos 88 milhões da população filipina trabalham no exterior em condiçôes legais ou ilegais. Esse crescimento se deu a partir da década de 1970 e foi decorrente de fatores internos e externos. De um lado, surge a demanda dos países do norte por mão de obra para os setores do cuidado (doméstico e da saúde). $\mathrm{Na}$ Inglaterra, onde se deu parte do trabalho de campo etnográfico, a demanda surgiu especialmente a partir do recrutamento sistemático de enfermeiras filipinas pelo Serviço Nacional Britânico de Saúde entre 1998 e 2005. De outro lado, o governo filipino firma uma série de políticas nacionais e bilaterais de incentivo à migração e in- corpora oficialmente tal fluxo como uma das bases econômicas do país.

Além da multiplicação no sentido quantitativo, houve também uma diversificação da experiência da migração, a começar pela sua feminização. Mães de família passam a sair de suas casas para trabalhar por anos em países mais ricos, vivenciando (in)interruptas migrações. Os filhos ficam sob os cuidados de outros parentes, especialmente avós e filhas primogênitas, e/ou de empregadas domésticas filipinas mais pobres, constituindo, assim, a denominada cadeia de cuidados. Sua ausência física, por vezes concomitante à do pai e de outros parentes, impóe o desafio de novos arranjos familiares marcados pela multiplicação de possibilidades de comunicação - e-mails, mensagens de texto (SMS), sites de redes sociais, webcam via VOIP (Voice over Internet Protocol). Ao longo do livro acompanhamos casos de mães migrantes que buscam garantir sua presença: telefonar regularmente para os filhos; deixar a webcam ligada por muitas horas, quando há condiçôes técnicas e financeiras, bem como horários livres compatíveis com o fuso-horário das Filipinas; intercambiar SMS que podem ser armazenados, lidos e relidos a qualquer momento; e possuir perfil em redes sociais, como Friendster e Facebook, constituem alguns dos meios pelos quais elas acompanham e interagem com os filhos.

Apesar das possibilidades oferecidas pelas mídias, os autores não subestimam tristezas e sofrimentos decorrentes das típicas experiências migratórias dessas mulheres, tampouco vitimizam suas famílias diante das desigualdades e injustiças expressas no contexto de migração. Não negam nem exaltam os dois extremos, mas os revelam a partir de ambivalências e contradiçôes inscritas nas narrativas dos informantes. Quando, por exemplo, no capítulo 3, "Why they go: and why they stay", discutem os motivos da migração de mães e da sua permanência prolongada no exterior, desvelam múltiplas camadas de significados que impedem o leitor de criar uma imagem estereotipada dessas mulheres e de suas condições. Objetivos normativos, como educação dos filhos e construção da casa própria, surgem como motivaçôes primeiras. Desigualdades de gênero e violência doméstica, anteriormente abordados por Parreñas (2001), 
costumam aparecer de forma tímida e indireta. $\mathrm{O}$ mesmo ocorre com motivos de ordem estrutural, como o desemprego e a ausência de um Estado de bem-estar social, e com os de ordem cultural, como um parentesco marcado pelo compartilhamento das responsabilidades sobre a casa e as crianças e uma prática migratória vivenciada por diferentes gêneros e geraçôes. Por fim, surgem as motivações de ordem pessoal que, atreladas às anteriores, levam as mulheres a decidirem pela sua permanência no exterior. Referenciados na reflexão de Constable (1999) sobre a complexidade das narrativas de trabalhadoras filipinas em Hong Kong em torno da permanência na migração, os autores mostram como as oportunidades de evolução e afirmação pessoal, o status social diante da família e as dificuldades de lidar com as ambivalências maternas são fatores determinantes na decisão dessas mulheres pelo prolongamento de sua estadia no exterior.

Se tivéssemos que qualificar a natureza dessa pesquisa em uma palavra, defini-la-íamos como comparativa. Primeiro, por conta de seu caráter diacrônico. No capítulo 4, "Letters and cassettes", Madianou e Miller apresentam a comunicação de outros tempos, quando ainda estava restrita a cartas e cassetes - situação que se contrapõe à diversidade de mídias dos tempos atuais, discutida posteriormente. Nesse capítulo histórico, vemos cartas escritas à mão e vozes gravadas em cassetes serem definidas pelo contraste entre suas características técnicas, bem como pela combinação entre tais características e os sentidos que elas ganham com seus usuários. Diferenças de interesses, grau de privacidade-publicidade, emoçôes, temporalidades e informações que umas e outras podem transmitir são alguns dos marcadores que as definem.

Outra dimensão da natureza comparativa da pesquisa está no contraste entre as perspectivas de mães migrantes e as dos filhos nas Filipinas. De um lado, mães despendem uma quantidade significativa de energia, tempo e dinheiro para criar seus filhos à distância e garantirem uma experiência de maternidade, segundo elas, "mais completa". No capítulo 5, "The mother's perspective", os autores mostram como a comunicação cotidiana via diferentes mídias cria condições para uma interação, na opiniāo delas, "mais real", incluindo os problemas e conflitos gerados pela separação física e temporal anteriormente silenciados. Mostram também como tal comunicação se torna tecnologias do self (Foucault, 1988) ao garantir meios de essas mulheres reconstituírem suas identidades maternas e negociarem a ambivalência entre sua vida profissional na Inglaterra e a familiar nas Filipinas. Não é à toa que muitas justificam a decisão de prolongar a migração a partir das possibilidades de cuidado materno por meio das novas mídias.

De outro lado, a visão dos filhos que ficaram nas Filipinas. De acordo com os dados apresentados no capítulo 6, "The children's perspective", uma parte deles vê e lida com a interação transnacional como uma tentativa malsucedida, e muitas vezes irritante, das mães em controlar suas vidas à distância. Essa mesma parcela acredita que as mídias proporcionam às migrantes menos uma possibilidade de (re)formulação de sua identidade materna do que a mera ilusão capaz de aliviar a culpa que sentem devido à ausência. Mas essa opinião não é generalizada. Há outra parcela que se aproxima da perspectiva materna e acha que a combinação entre distância física, cuidado e controle por meio das mídias torna a relação mais fácil e, algumas vezes, mais forte e próxima, em especial na fase da adolescência. Segundo Madianou e Miller, a opinião positiva ou negativa dos filhos é fortemente marcada por três fatores, quais sejam, a idade deles quando a mãe migra, a qualidade da relação antes da migração e a variedade das mídias disponíveis para a comunicação transnacional.

Por fim, a terceira dimensão da natureza comparativa da pesquisa está na definição contrastiva de cada uma das mídias. Os autores, no capítulo 7, "The technology of relationships", classificam-nas a partir de três tipos de comunicação: 1) baseada na voz (ligaçôes telefônicas entre celulares, cartão internacional para celular, cartão internacional para telefone fixo, ligações VOIP de PC para PC e de PC para celular, fita cassete); 2) baseada em texto (e-mail, chat, SMS e cartas); 3) multimídia (sites de redes sociais, skype etc.). Os usos e sentidos que cada mídia tem para mães e filhos nos apresentam uma noção de tecnologia mais em termos de possibilidades que ela oferece para a ação (affordances) do que como determinantes da ação (Hutchby, 
2001). Em outras palavras, a possibilidade de ação de cada uma delas é definida a partir da interseção de marcadores sociotécnicos, tais como interatividade, temporalidade, capacidade de armazenamento, durabilidade do conteúdo, replicabilidade, alcance e visibilidade, mobilidade, pistas, natureza pública/privada, custo e capacidade informacional.

Contudo, esta definição é parcial, traçada com base apenas nas capacidades técnicas. De acordo com os argumentos do capítulo 8, "Polymedia", os dados de campo sugerem pensar a constituição de cada uma das mídias a partir não apenas de tais capacidades, mas também da interação destas com fatores sociais. Para ser mais precisa, sua constituição deve ser analisada nos movimentos de interação entre diferentes fatores sociais - como o contexto político e econômico, as condições de vidas das pessoas envolvidas, os idiomas da prática, as ideologias das mídias e, é claro, as relações sociais - e entre esses fatores, as características técnicas das mídias e suas possibilidades de ação. Tais movimentos constituem a polimídia, um amplo ambiente de oportunidades comunicativas onde as affordances ganham contornos.

A polimídia é definida como uma espécie de estruturalismo no qual o entendimento que temos de cada uma das mídias é resultado do seu contraste com outras que também poderiam ser utilizadas numa mesma comunicação. Os e-mails, por exemplo, só são definidos como tais nas suas diferenças em determinado contexto e em relação a telefones, cartas e SMS. Ou seja, os contrastes e as sinergias entre as tecnologias em uso definem o nicho de cada uma delas em certo contexto pessoal e cultural. Concomitantemente, esses contrastes e sinergias tornam-se o idioma por meio do qual as pessoas expressam as diferenças de forma e propósito da própria comunicação. Nesse sentido, toda escolha por uma ou outra mídia é um ato comunicativo e moral definidor de cada uma delas. É também um ato a ser compreendido de acordo com formas culturais de socialidade, temporalidade, poder e emoção. ${ }^{1}$

Concluída a análise sobre as tecnologias, os autores voltam atenção para as relaçôes sociais. No ultimo capítulo da obra, "A theory of mediated relationships", apresentam uma proposta teórica para tratar das relações sociais mediadas, pensada a partir da maternidade transnacional entre as filipinas. De acordo com eles, os casos em questão constituem o extremo de um dilema que pessoas em co-presença enfrentam cotidianamente, a saber, a natureza mediada das relaçōes sociais. Com base no trabalho de campo e em estudos de Miller (1997 e 2007), argumentam que as relações sociais, entre elas a maternidade, são a síntese da dialética entre o parentesco normativo e o experiencial: as partes envolvidas se esforçam para reter princípios formais, no que se refere a tais categorias modelares (mais ou menos modernas; mais ou menos filipinas), diante da complexidade de suas vidas cotidianas no universo transnacional. Dito de outra forma, as relações sociais são resultado da tensão entre a manutenção de expectativas formais e a diversidade de experiências vivenciadas no dia a dia. Nesse sentido, toda relação é mediada.

Portanto, não é de se surpreender que filipinas migrantes compartilhem com tantas outras mães trabalhadoras as "contradições culturais da maternidade" (Hays, 1997), contradiçôes que as colocam diante da necessidade de negociar seus diversos papéis e identidades na vida profissional e familiar. Sua particularidade está no fato de terem que lidar com essa tensão no contexto transnacional. Com a distância físico-temporal, os ideais normativos tornam-se mais distantes da pessoa que ocupa uma das posiçóes. Nesses casos, as mídias acionadas nas conversas entre mães e filhos carregam o esforço de torná-los cientes do modo como cada um quer que o outro seja e também como este outro deveria querer o mesmo para si. Em suma, as mídias medeiam a tensão que marca a natureza mediada de toda e qualquer relação.

Migration and new media é um convite ao deslocamento por entre "entendimentos nativos" e "entendimentos científicos". Como uma boa viagem etnográfica, cruza fronteiras territoriais, metodológicas e disciplinares e apresenta um interessante ensaio teórico para leitores interessados em maternidade, migração, mídias e relações sociais. A cada vai e vem, somos conduzidos por uma narrativa de encontros, e também desencontros, na qual a imensidão da distância espaço-temporal se (con) funde com a imensidão das relações sociais em uma verdadeira dialética chamada maternidade. 


\section{Notas}

1 Sem dúvida, uma das contribuições da teoria da polimídia é a reflexão em torno das possibilidades das pessoas em criar registros e repertórios emocionais variados no (e a partir do) ambiente polimidiático. Nesse caso, as mídias não apenas transmitem e moldam as emoções; mas a simples escolha por uma ou outra mídia constitui a expressão mesma das emoções.

\section{BIBLIOGRAFIA}

CONSTABLE, Nicole. (1999), "At home but not at home: Filipina narratives of ambivalent returns”. Cultural Anthropology, 14 (2): 203-228.

FOUCAULT, Michel. (1988), "Technologies of the self", in L. H. Martin et al., Technologies of the self: a seminar with Michel Foucault, Londres, Tavistock.

HAYS, Sharon. (1997), The cultural contradictions of motherhood. New Haven, Yale University Press.

HUTCHBY, Ian. (2001), “Technologies, texts and affordances”. Sociology, 35 (2): 441-456.

MILLER, Daniel. (1997), "How infants grow mothers in north London". Theory, Culture and Society, 14 (4): 67-88. . (2007),"What is a relationship? Kinship as negotiated experience". Ethnos, 72 (4): 535-554.

PARREÑAS, Rhacel Salazar. (2001), Servants of globalization: women, migration and domestic work. California, Stanford University Press.

BRUNA LOUZADA BUMACHAR é doutoranda do Programa de Pós-Graduação em Antropologia Social da Universidade de Campinas (Unicamp) e bolsista da Fundação de Amparo à Pesquisa do Estado de São Paulo (Fapesp). E-mail: <brunabumachar@ yahoo.com.br>. 